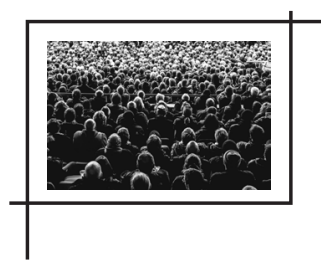

\title{
DESIGN DE MODA E ENGAJAMENTO SOCIOPOLÍTICO
}

\author{
Isabella Perrotta* \\ Gabriela Pinti Stocco Moreira** \\ Patricia Mendonça Lima*** \\ Juliana Meira****
}

Resumo: Esse artigo trata da relação da moda com propósitos e engajamentos, com base na conexão que foi percebida em três pesquisas, aparentemente bastante distintas, que ocorriam paralelamente na mesma instituição em 2018/2019: uma de iniciação científica, sobre o empoderamento feminino na estética de fanzines do punk rock; uma de mestrado, sobre as tendências no processo de decisão de compra de moda, no Rio de Janeiro; e outra também de mestrado, sobre a moda como um possivel veículo para a discussão, e sensibilização, em relação aos altos índices de mortalidade de jovens negros no Rio de Janeiro. De alguma forma, as pesquisas perpassam a possibilidade de a moda cumprir uma função comunicacional, tanto como vetor de engajamento para seus usuários (a primeira e a terceira) quanto como reflexo do engajamento de seus consumidores (a segunda). As três pesquisas partiram de referencial bibliográfico, mas desdobraram-se diferentemente: a primeira envolveu análise documental (no que tange à análise gráfica de uma seleção de fanzines); a segunda abrangeu uma pesquisa qualitativa aprofundada (baseada em entrevistas e grupos focais); e a terceira analisou estudos de casos variados, propondo, ao final, a materialidade de uma plataforma colaborativa. A relação da tecnologia com a forma de consumo das novas gerações está presente no segundo e no terceiro trabalhos. Este artigo partiu dos processos e dos resultados desses trabalhos, mas trouxe outras contribuições em relação às referências bibliográficas.

Palavras-chave: Moda. Rebeldia. Propósito e ativismo. Tendências de consumo para o futuro próximo. Tecnologia.

\footnotetext{
* Doutora em História pela Fundação Getulio Vargas (FGV). Mestre em Design pela Pontifícia Universidade Católica do Rio de Janeiro (PUC-Rio). Coordenadora do Mestrado em Economia Criativa da Escola Superior de Propaganda e Marketing (ESPM-Rio).E-mail: iperrotta@espm.br

** Mestra em Economia Criativa pela Escola Superior de Propaganda e Marketing (ESPM-Rio).E-mail: ga.stocco@gmail.com

*** Mestra em Economia Criativa pela Escola Superior de Propaganda e Marketing (ESPM-Rio). E-mail: patriciamendoncalima@ gmail.com

**** Designer pela Escola Superior de Propaganda e Marketing (ESPM-Rio), pesquisadora de iniciação científica. E-mail: julianameira76@hotmail.com
} 


\section{INTRODUÇÃO}

Em crônica de janeiro de 2019, o jornalista, compositor e produtor musical Nelson Motta recorda-se do ano de 1967: no Brasil, vivia-se uma ditadura militar que censurava teatro, cinema, livros, jornais e ideias, e ele ia a Nova York pela primeira vez. Em Manhattan, deparou com uma loja que vendia, por apenas 1 dólar, pôsteres em preto e branco de personalidades ideológicas como Trotsky, Marx, Engels e Luther King, além de outras do mundo pop, como Elvis Presley e Marlon Brando. Imagens que, além de decorar, davam "identidade à sua casa, diziam quem você era" (MOTA, 2019). Porém, sua maior surpresa, naquela metrópole do capitalismo, seria as camisetas com o retrato do revolucionário argentino, e herói cubano, Che Guevara, que fazia um enorme sucesso entre os jovens.

A camiseta do Che (foto de Alberto Korda, trabalhada em alto contraste por Jim Fitzpatrick), ainda hoje à venda, inaugurava uma tendência que nunca mais sucumbiu. Essa peça do vestuário passou a ser um outdoor ambulante, que mais do que qualquer outra função - prática ou estética -, passou a exercer a de meio de expressão e plataforma de divulgação do que o seu usuário pensa.

A camiseta branca, concebida como uma singela roupa de baixo masculina, nos anos 1950 passa a ser usada como peça de estilo esportivo. Combinada com a calça jeans e a jaqueta de couro, passou a ser símbolo de rebeldia, perpetuado na imagem do ator hollywoodiano James Dean. Na década de 1960, já como uma roupa unissex, esteve diretamente relacionada com a estética hippie, tanto no que diz respeito à exposição de símbolos (como o do desarmamento nuclear) e expressões (como "paz e amor") nela impressos quanto aos desenhos psicodélicos e às pinturas com técnicas artesanais como o silkscreen, o batike o tie-dye; e ainda os bordados.

A partir dos anos 1960, então, a indústria formal da moda começou a olhar para as categorias geracionais e, inclusive, ajudou a delineá-las. Nascia o conceito de moda jovem, em geral também desenvolvido por jovens criadores: "um ano basta para um jovem confeccionista adquirir uma atitude experiente. Virar estrela, o sonho geral" (RODRIGUES, 1994, p. 7).

Muito mais recentemente, pesquisadores começaram a mapear o comportamento do consumidor, inclusive as forças emergentes que vêm caracterizando as mudanças de comportamento a cada geração. Hoje é muito comum o uso da classificação internacional, a seguir relacionada, para designar as gerações.

Baby boomers compõem a geração nascida na explosão demográfica ocorrida pós-Segunda Guerra, especificamente entre 1945 e 1964; Geração X é aquela de indivíduos nascidos entre 1965 e 1979; millennials (ou geração Y) são os nascidos entre o final do século XX (1980) e início do XXI (1994), que se desenvolveram em um momento de prosperidade econômica e presenciaram uma das maiores revoluções da história da humanidade: a internet; e a geração Z abrange os nascidos a partir de 1995. 
As características de cada uma das categorias geracionais estão relacionadas a momentos da economia e da política global, e a todo um conjunto contextual que influencia seus valores, sua relação com família, emprego, trabalho e sociedade e, claro, com consumo, estilo de vida e forma de se vestir. Contudo, muitos defendem que é principalmente o acesso à tecnologia que define as gerações, estando ela completamente relacionada com a forma de consumir. Considerando essa questão, principalmente a geração $Y$ brasileira teria uma sensivel defasagem em relação à americana. Por isso, institutos de pesquisa locais costumam usar outra métrica para definir as gerações: X, de 1965 a 1984; Y, de 1985 a 1999 e Z, de 2000 até hoje. Contudo, a recente tendência dos institutos é acreditar que não existem mais classes sociais distintas - mas comportamentos de compras distintos. Assim, a classificação geracional vem sendo substituida pelo entendimento de geração perennials ou ageless, ou seja: o desenho do comportamento e do consumo de um grupo não é dado pela idade, mas pela sua identidade.

\section{DO HIPPIE AO PUNK}

Se um visual rebelde começou a surgir nos anos 1950 para caracterizar uma nova juventude, a década de 1960 esteve fortemente relacionada com o movimento hippie, para o qual uma estética de vigoroso apelo visual era uma forma de chamar a atenção para seus valores, que se opunham às tradições. Para os jovens, além de ser hippie, era necessário parecer hippie, comunicar ser hippie: jeans desbotados e rasgados, roupas largas, estampas floridas (o "flower power" era um dos seus lemas), e muitas peças artesanais em couro, crochê ou bordados, pois o movimento contestava o capitalismo, defendendo o Do It Yourself (DIY- ou "faça você mesmo").

Outras vertentes de "moda jovem" - termo que surgia baseado em lojas e marcas específicas - caracterizaram a estética dos anos 1960. Muitas vezes, em total antagonismo em relação aos lemas hippies, como foi o caso da vertente futurista, ou o próprio psicodelismo não hippie, mas high tech. "A razão de tantos estilos diferentes pode vir do fato de as pessoas que ditam a moda não serem mais as de antes" (GONTIJO, 1987, p. 93).

A minissaia talvez tenha sido um dos principais icones da moda do periodo, intrinsecamente relacionada à liberação sexual feminina e ao novo papel da mulher moderna na sociedade. Uma das responsáveis pelo seu sucesso foi a estilista Mary Quant, que estava onde os Beatles - e outras bandas que inspiravam os jovens - estavam: em Londres. Porém, enquanto "Mary Quant modificava a aparência das moças, em Paris é lançado um novo estilo; trata-se da moda unissex, [...] camisa e calça em jeans mais leves que o da calça Lee, famosa na época" (GONTIJO, 1987, p. 94). Em Londres também estava a modelo Twiggy, que, apesar de ter sido uma das principais embaixadoras da minissaia, lançou-se com uma estética quase andrógina: cabelos curtíssimos e jeito de menino levado. 
Nos anos 1970, a Inglaterra estava dominada por uma profunda crise econômica e grande insatisfação popular, que levaria ao surgimento de um novo movimento musical que invocava a juventude politizada - e consciente dos problemas que assolavam o pais - a clamar por uma revolução e pela ruptura com a geração anterior. Nascia o movimento musical punk rock. Por meio de atitudes polêmicas e visual agressivo, seus músicos rompiam com as atitudes esperançosas e otimistas dos hippies. Os punks demonstravam violência e desespero tal como a declaração do cineasta Julien Temple no documentário O lixo e a fúria (The filth and fury): "o punk não pretendia deixar as pessoas felizes, tratava-se de um ataque punk"1 (THE FILTH..., 2000, tradução nossa).

Credita-se à banda inglesa Sex Pistols, formada em 1975, a criação do estilo. Embora tenha tido curta trajetória (apenas até 1978), teria influenciado diversos músicos e outras bandas. Seu incendiário single "God save the queen"2, lançado em 1977 - no momento das comemorações do jubileu de prata do reinado da rainha Elizabeth -, atacava o conformismo e as tradições britânicas, sendo por isso glorificado e também execrado. Tanto que os trabaIhadores de uma fábrica de discos se recusaram a prensá-lo, rádios se recusavam a tocá-lo e os editoriais recusaram-se a reconhecer sua posição no topo das paradas (O'HAGAN, 2004).

Além disso, o contrato com o selo americano ActM Records para esse lançamento foi rompido dias após sua assinatura, pois a empresa não suportou o comportamento punk dos artistas "na vida real", o que a levou a descartar milhares de discos já prensados e também a camiseta promocional com o retrato da rainha com os olhos e a boca cobertos por inscrições - em letras sujas, como se fossem de jornal recortado - com os nomes do disco e da banda. As peças remanescentes viraram objeto de desejo e até hoje são reproduzidas e vendidas em larga escala (GORDON, 2017).

Todavia, assim como o movimento hippie, o punk não coube numa inscrição de camiseta. Ele foi toda uma estética que, para além do estilo musical, queria identificar uma geração que rompia padrões e opunha-se a tradições.

0 estudante de arte Malcolm McLaren, mentor da Sex Pistols, e sua então companheira, Vivienne Westwood, mantiveram, desde 1971, uma loja de roupas na icônica King's Road de Londres (já famosa nos anos 1960 por causa de Mary Quant e de outros estilistas jovens e modernos). A loja mudou de nome várias vezes, mas foi "catalisadora de uma moda que aos poucos se tornou cada vez mais escandalosa, continuamente reinventando ideias de sadomasoquismo e fetichismo" (DRUSCO, 2010). McLaren e Westwood criaram um conjunto de mercadorias situacionistas (CLARKE; HOLT, 2016), ou seja, relacionadas ao movimento europeu situacionista que se caracterizava pela crítica social, cultural e política. Esse movimento

1 - No original: "punk didn't try to make people happy, it was an attack".

2 - Mesmo nome do hino nacional do Reino Unido. 
reuniu poetas, arquitetos, artistas plásticos e cineastas que rejeitavam a autoridade capitalista, vendo, como sua missão, subverter e desafiar o status quo burguês (DEBORD, 1997). E a loja seguia influenciando o estilo de outras da mesma rua... daquela região da cidade saiu o figurino de punkeiros e motoqueiros, de Londres para o mundo: calças de borracha, camisetas pretas justas e com zíperes no peito, alfinetes de segurança espetados nas roupas, correntes, colares, sapatos tacheados etc.

Entre o final dos anos 1970 e o início dos 1980, um dos elementos estéticos que mais marcava a cultura punk era o corte de cabelo introduzido pelo vocalista Wattie Buchan, inspirado nos índios moicanos americanos. 0 corte caracteriza-se por uma "crista" de cabelo no meio da cabeça raspada e representava - tal como a luta daquela cultura indígena - uma posição contra o sistema.

As características musicais punk, embora tenham quebrado regras, tornaram-se rapidamente "uma tradição - um movimento com valores estilísticos extremamente previsiveis" (HENRY, 1989, p. 115). 0 que também se deu com a estética do movimento. Por isso, talvez a imprevisibilidade que restasse à sua criadora fosse uma dose de mainstream.

Em 1981, Westwood e McLaren tiveram uma virada estética para o lado romântico, com influências de referências históricas, e, pela primeira vez, desfilaram nas passarelas oficiais da moda (DRUSCO, 2010). Em 1983, com o fim de seu relacionamento, McLaren concentrou-se na música, ganhando ao longo dos anos um visual quase conservador; Westwood continuou no mundo da moda. Ela é persistentemente acusada de hipocrisia por ser crítica ardorosa da sociedade de consumo e por colocar seu trabalho à disposição de causas de grupos ambientalistas, embora ela própria, e sua empresa, estejam - como qualquer outra marca - atreladas ao consumo, incitando um ciclo de produção, promoção e consumo sazonais e efêmeros.

\section{O CASO VIVIENNE WESTWOOD}

Existem forças que aceleram os ciclos de consumo da moda: a fascinação da mídia pela moda, inclinando-se a relacioná-la com arte e cultura; a exploração contemporânea da tecnologia digital, que permite que consumidores comprem on-line, e em tempo real, enquanto visualizam na passarela coleções de microestações que interrompem o tradicional enquadramento sazonal, de duas coleções por ano; e o fenômeno fast-fashion, uma resposta a uma crescente demanda por moda barata, que levou as lojas a prepararem novas coleções em apenas três semanas, resultando em roupas concebidas para serem quase descartáveis (CLARKE; HOLT, 2016). Vivienne Westwood, ainda hoje no mercado de moda, está envolvida nesse processo como um todo, embora sua crítica à sociedade de consumo tenha tomado forma em apoios explícitos a movimentos e ONGs, inclusive imprimindo slogans ativistas em suas roupas. 
Instigados pela contradição capitalismo vs. engajamento em Westwood, os professores ingleses Jean Clarke e Robin Holt dedicaram uma pesquisa para investigar sua marca e seus consumidores. 0 artigo, que discute a pesquisa, procura mostrar como a ética no consumo é um engajamento crítico que aparece na compra e no uso, e no entendimento dos valores dos produtos. Segundo o paper, os consumidores engajados acompanham o trabalho das marcas e refletem mais sobre suas decisões de consumo, em vez de satisfazer os seus desejos imediatos.

0 trabalho ainda lembra que são muitas as empresas de moda que já reagiram à má publicidade à qual ficaram atreladas, adotando posturas sociais e ambientais, promovendo campanhas de sustentabilidade e empregando grupos cooperativos, entre outras ações. Aumentar a transparência das cadeias de suprimentos, por exemplo, faz que as empresas invistam em melhores condições de trabalho, instalando sistemas de proteção ambiental e considerando métodos de produção menos agressivos, com maior preocupação com o impacto sobre os outros. Os pesquisadores, contudo, chamam a atenção para o fato de que as críticas continuam, pois a moda estimula o consumo rápido e efêmero e, portanto, o desperdício, expondo o consumidor à comercialização da filantropia.

A coleta de dados de Clarke e Holt em relação a Westwood envolveu entrevistas individuais semiestruturadas e em profundidade com respondentes que mantinham relação de longa data com a designer, tanto como funcionários quanto como clientes; consulta a documentos primários da empresa e à literatura secundária; observação participante e entrevistas informais junto à produção, a funcionários e a clientes. 0 resultado da pesquisa sugere que a estilista possibilita a experimentação de uma moda ética por seus clientes, que também podem ser vistos como consumidores éticos. Eles estão cientes da alegria que as roupas podem trazer e, ao mesmo tempo, são cautelosos em relação à moda produzida de forma rápida e barata, à custa de exploração social e do pouco respeito ao meio ambiente. São bem informados sobre a maneira como as roupas são feitas e sentem-se parte da história da marca. 0 estudo mostrou como o envolvimento ativo dos consumidores não é apenas importante para a viabilidade comercial da marca, mas envolve-os em uma criação engajada e crítica.

Para os pesquisadores, Westwood ainda se mantém coerente em relação aos seus princípios, mas não está claro, contudo, se sua marca continuará alinhada com as ideias de consumo ético, pois a investigação também ouviu críticas como a de uma funcionária que informou que a empresa recebe grandes encomendas de roupas da Turquia, Malásia e Indonésia, com uma grande quantidade de papel e caixas que são desperdiçadas. "Chega a ser embaraçoso" - foi dito. Outra funcionária comparou a antiga pequena butique, onde se tocava a campainha da porta e se recebiam as clientes com um "Oi, como você está?", com a grande loja de agora, que funciona com as portas abertas. "É quase como se alguém entrasse e saísse e você nunca pudesse falar com eles, nunca descobrisse o que eles gostam ou o que eles não gostam" (CLARKE; HOLT, 2016, p. 43). Entretanto, a designer não parece descontente: 
Estou mais interessada no que estou fazendo agora, mas o que preciso explicar é o seguinte: o que estou fazendo agora ainda é punk... ainda tem a ver com gritar a respeito da injustiça e fazer as pessoas pensarem, mesmo que seja desconfortável. Sempre serei uma punk nesse sentido. 0 punk, para mim e para Malcolm, e na loja, se tornou uma espécie de bricolagem: juntando ideias. Juntando pessoas (KELLY; WESTWOOD, 2014, p. 147).

E a estilista inglesa persiste com as camisetas. Nas primeiras, que chocavam uma Inglaterra conservadora dos anos 1970, apareciam cowboys homossexuais e suásticas junto à rainha. Numa das recentes, grifou: "Eu não sou terrorista, por favor não me prenda" em protesto contra as leis antiterroristas adotadas pelo governo britânico, depois de um atentado ao metrô em 2005 (KELLY; WESTWOOD, 2014).

\section{O NOVO CONSUMIDOR: O QUE AS PESOUISAS DE TENDÊNCIAS APONTAM}

Recentes pesquisas de empresas globais de tendências e inteligência de mercado, como Euromonitor International e WGSN, apontam como principais caracteristicas de comportamento do consumidor, para a década de 2020, o uso da tecnologia móvel e da informação em rede, tanto como suportes para a decisão de compras quanto para o engajamento em relação a causas.

A pesquisa da Euromonitor, assinada por Alison Angus (2017), desenhou dez perfis de consumidores, apresentados a seguir. A pesquisa não indica que as categorias são excludentes, por isso entende-se que um mesmo consumidor pode ter traços de diferentes perfis.

1) Clean lifers: são consumidores jovens, que têm fortes crenças e ideais e adotam estilos de vida simples e minimalistas, em que a moderação e a integridade são fundamentais. Sentem que podem fazer a diferença e isso influencia suas escolhas de gastos. Dizem não ao álcool, aos produtos de origem animal, aos gastos desmedidos ou desinformados e aos hábitos não saudáveis. Querem impressionar menos pelas posses e mais pelas experiências. Tendem a morar na casa dos pais por mais tempo, principalmente em locais onde os custos para morar sozinhos são proibitivos.

2) The borrowers: são preocupados com a comunidade e veem o consumo ostentatório como coisa do passado. Preferem o acesso à propriedade - seja por meio de compartilhamento, troca, aluguel ou transmissão. 0 perfil impacta também as gerações mais velhas Baby boomers, antes materialistas, que agora estão buscando simplificar suas vidas compartilhando os novos sustentáculos da economia, como Uber, Airbnb ou Rent the Runway ${ }^{3}$. Essa

3 - Empresa de terceirização de roupas. 
economia on demand fornece aos próprios consumidores fluxos de receita adicionais quando compartilham o que eles têm, sejam habilidades, sejam bens. Por causa deles, grandes empresas estão sendo forçadas a repensar seus modelos de negócios para se adaptar à nova mentalidade dos "mutuários".

3) Call out culture: são consumidores empoderados pelas midias sociais que usam a voz coletiva para chamar a atenção para injustiças e clamar as marcas para prestar conta de seus atos. Enquanto no passado os consumidores podem ter se sentido impotentes para enfrentar as grandes marcas, agora as mídias sociais Ihes deram influência coletiva. Em 2017, usuários do Instagram, Tumblr, Facebook e outros geraram 125 milhões de hashtags para assinar petições e apoiar causas.

4) It's in the DNA - I'm so special: são pessoas cada vez mais interessadas em sua constituição genética e os reflexos disso na demanda por serviços de saúde e beleza personalizados. Grupo que inclui preocupados, curiosos e fanáticos por fitness e nutrição. As empresas atentas à demanda especializam-se em mapeamento do código genético a partir de amostras de sangue ou saliva. Esse mercado ainda enfrenta obstáculos quanto a regulamentações, além de limitações sobre o conhecimento do assunto, por isso, as empresas precisarão ser claras e diretas sobre as suas limitações, ou estarão arriscando perder a confiança do consumidor.

5) Adaptative entrepreneurs: é um grupo de consumidores em busca de flexibilidade e de um "estilo de vida empreendedor adaptável" que os afastam das carreiras tradicionais em direção àquelas que oferecem mais liberdade. São principalmente millennials, mas a pesquisa aponta que quase 50\%, de todas as gerações, aspiram a ser autônomos. Entre os fatores apontados para a rejeição a empregos e a empresas tradicionais estão o fato de os salários estarem estagnados e o índice recorde de jovens desempregados em muitos países.

6) View in roomers: são aqueles que só compram pelas lojas on-line, mas testam virtualmente os produtos antes de comprar, usando smartphones de última geração e realidade aumentada, para ter uma visão "real" do que desejam, dissipando qualquer incerteza. Considerando que as compras on-line têm um enorme índice de retorno de produtos - o que é caro e frustrante para as empresas -, a realidade aumentada tem sido uma possibilidade de melhorar a experiência do consumidor, proporcionando uma visão mais realista dos itens a serem escolhidos, facilitando a eficiência operacional das empresas e reduzindo potencialmente suas taxas de retorno. Por isso, a Amazon lançou, em 2017, o AR View - aplicativo de visualização de produtos reais on-line.

7) Sleuthy shoppers: esse grupo é formado por consumidores pesquisadores. Céticos em relação aos produtos produzidos em massa, às motivações das empresas que os criam e suas retóricas vazias, eles estão tomando medidas para descobrir mais sobre o que consomem. Sérios sobre suas causas, procuram as informações disponiveis sobre empresas e produtos. Representantes das gerações X e Z, são sobreviventes da recessão. Para construir 
a confiança desses consumidores, as empresas devem oferecer provas detalhadas sobre sua cadeia de suprimentos e práticas trabalhistas e, de preferência, acrescidas da certificação de terceiros.

8) I-designers: são representantes dos grupos millennials e Xers, que têm reavaliado seus hábitos de compra para além das questões ligadas ao compartilhamento e ao consumo responsável. Querem participar dos processos de criação e fabricação de seus produtos. Anseiam por mais autenticidade e verdadeira personalização de suas compras, que são ostentadas nas redes sociais sob a legenda "foi feito por mim". Estão assumindo o papel de criadores, não apenas na escolha de cores ou na personalização de detalhes de itens produzidos em massa, mas realmente os moldando de acordo com suas preferências e necessidades individuais. Assim, cada vez mais, as empresas disponibilizam ferramentas que permitem aos clientes desenvolverem produtos.

9) Co-living: é um grupo que abrange desde os millennials até a geração com mais de 65 anos, que dividem espaços de moradia, além de um conjunto de interesses e valores, tanto para economizar dinheiro e obter condições de vida mais confortáveis e mais aceitáveis quanto para inspirar ideias colaborativas. A tendência é característica dos centros hiperurbanos, onde os preços dos imóveis estão muito altos, e decorrente da economia compartiIhada como uma escolha de estilo de vida.

10) The survivors: são aqueles que passaram pela grande recessão de dez anos atrás e, apesar da melhora econômica, continuam lutando para lidar com a austeridade. Estão na parte inferior da pirâmide, muitas vezes dependendo de escassos benefícios estatais ou da ajuda de instituições não governamentais. Têm empregos precários e compram, em lojas físicas, itens de segunda mão, escolhidos em função do valor e da forma de pagamento. Suas compras estão mais relacionadas a itens de primeira necessidade e menos a lazer. Em função deles, na Europa, surgiram "supermercados sociais", que vendem alimentos com datas de validade próxima, rótulos incorretos ou embalagens danificadas com descontos de até $50 \%$.

Os resultados da pesquisa 0 consumidor do futuro 2020, da WGSN, produzida em 2018, também foram consultados para este artigo. Eles foram apresentados numa matriz dividida em: fatores globais, prioridades do consumidor e perfis do consumidor. Os fatores globais preponderantes são: as novas vozes das novas maiorias étnicas, raciais e religiosas; a força transformadora da tecnologia 5G, principalmente em relação à adoção da realidade aumentada e das experiências virtuais; e a integração entre a economia compartilhada e o capitalismo comunitário e ativista, com consumidores lutando para que o seu dinheiro seja investido localmente. As prioridades do consumidor são: o ativismo analógico, o combate à ansiedade e o uso de tecnologia de forma responsável.

Importante destacar que as tendências de consumo apontam que o mercado hoje segmenta-se menos por classes sociais e gerações, e mais por comportamento de compra, 
empregando-se, inclusive, os conceitos de ageless e perennials para tentar descrever esse novo consumidor.

Em decorrência desses fatores e prioridades, apresentados anteriormente, a pesquisa da WGSN (2018) estabeleceu os seguintes perfis do consumidor:

1) Localtivistas: esse grupo de consumidores, segundo a WGSN, seria uma consequência dos movimentos ativistas analógicos - aqueles que não acreditam nas ruas. Eles valorizam a produção local e são superconscientes das questões sociais e ambientais, mas, ainda assim, são conectados, urbanos e querem manter o dinheiro dentro de suas comunidades. Desmitificam o lema "o que vem de fora é melhor" e a clássica valorização de produtos importados, nos paises periféricos. Para esse grupo, não adianta o discurso, mas sim o contexto, a prática, a economia local. Entendem que a riqueza humana está além do capitalismo e preocupam-se, acima de tudo, em melhorar a vida da sua comunidade.

2) Imperfeccionistas: esse grupo é decorrente dos movimentos de combate aos grandes indices de ansiedade contemporânea (muitos deles relacionados com as pressões da publicidade em relação ao consumo). São movimentos globais que valorizam a imperfeição e os momentos tranquilos, admitindo que não conseguimos estar em todos os lugares e fazer tudo ao mesmo tempo. Esse consumidor quer viver num mundo onde não precise ser o melhor ou lindo e faz piadas sobre os padrões de beleza inatingiveis. Para ele, é importante ter soluções menos massificadas, mas sim segmentadas, sem seguir padrões preestabelecidos. 0 impacto de suas prioridades tem aumentado o mercado de bem-estar, incluindo turismo e beleza, saúde e exercícios.

3) Aumentalistas: ao contrário dos imperfeccionistas, estes valorizam ao máximo a tecnologia, otimizando a vida e a evolução humana. São a maioria da população. Entretanto, cada vez mais, exigem o uso da tecnologia de forma responsável, defendem seus avanços, mas querem que a vida seja otimizada e integrada - não consumida - por ela. Além das reações do cidadão comum, acionistas e governos estão agindo pela causa. Esse grupo é atraído por empresas e produtos que estão na vanguarda da inovação. Depois da tecnologia de voz, a próxima etapa serão os gestos - ações como agitar, girar, inclinar, um deslizar de dedos, um gesto no ar serão parte da interface do usuário, com o intuito de criar experiências mais ricas e simples, estimulando a usabilidade.

Esses três perfis, desenhados pela WGSN, foram o ponto de partida para a pesquisa de Gabriela Stocco (2019), que buscou desenhar as tendências de compra que estão se configurando no varejo de roupas femininas do Rio de Janeiro entre as classes A e B. Ela se utilizou da pesquisa qualitativa com o objetivo de identificar as motivações de compra, assim como as atitudes, comportamentos e a existência ou não de preocupações com causas, no ato do consumo de moda, por jovens cariocas. A pesquisa foi baseada em entrevistas semiestruturadas em profundidade e um minigrupo focal, totalizando nove respondentes que estavam 
dentro dos seguintes parâmetros: mulheres entre 24 e 34 anos, residentes em bairros da zona sul do Rio de Janeiro. Foram identificados três perfis de consumidoras chamados de consumista (quatro respondentes), no caminho (quatro respondentes), e sempre consciente (um respondente). Em todos os perfis foram identificadas caracteristicas localtivistas (WGSN, 2018), assim como sinais da presença de uma consciência ambiental e social em desenvolvimento, não só em relação à moda, mas a diferentes aspectos da vida. Contudo, as consumistas, apesar de compreenderem o impacto do alto consumo e terem conhecimento das notícias de escândalos envolvendo grandes marcas com trabalho escravo, não chegam a ser influenciadas por isso no momento da compra. Admiram o consumo de marcas menores ou mais sustentáveis, mas o que determina a compra, para elas, é a realização sentida pela aquisição de um produto desejado. Elas costumam revender as peças que estão excedendo em seus guarda-roupas, mais do que doá-las. Já as consumidoras no caminho não têm o costume de revender suas roupas porque não têm muitas peças sem uso, e acreditam que o trabalho de fazê-lo não compensa. Tampouco têm o costume de comprar peças de segunda mão, apesar de manifestarem a vontade de praticar mais tal possibilidade. Apresentam nivel de consciência socioambiental médio/alto, mas sabem que podem, e até desejam, exercitá-la mais. Para a respondente sempre consciente, ir às compras é quase um martírio, que evita ao máximo. Quando compra alguma roupa, usa sempre ao máximo aquela peça. Nunca teve nenhuma relação de afeto com marcas, embora goste de acompanhar algumas como inspiração de estilo. Contudo - pelo preço -, não as compra. Praticamente não compra nas redes de fast-fashion, com alguma exceção para peças muito específicas, geralmente no exterior.

\section{MODA ENGAJADA NA CAUSA DA VIOLÊNCIA NO RIO}

Pelo que foi apresentado até aqui, pode-se dizer que a moda funciona como um reflexo das transformações sociais do mundo. Além disso, considerando-se que os consumidores, inclusive os de moda, estão cada vez mais preocupados com a história/procedência dos produtos que consomem, e cada vez mais engajados em causas, pode-se vislumbrar que a moda pode ser usada como plataforma de "comunicação acontecimal" (LIPOVETSKY; SERROY, 2015), posto que o mundo contemporâneo, segundo o filósofo, é hiperestetizado e hiperconsumista.

$\mathrm{Na}$ era do capitalismo transestético, a arte se impõe como uma ferramenta de "comunicação acontecimental" que permite enobrecer as marcas, criar uma imagem audaciosa, criativa, menos mercantil. Por esse caminho, a marca efetua uma espécie de transmutação simbólica, exibindo-se alinhada à gratuidade, à doação generosa (LIPOVETSKY; SERROY, 2015, p. 53). 
Percebendo a função social da moda, Lima (2019) propõe que a roupa, especialmente a camiseta, seja veículo e estratégia de sensibilização para a causa da mortalidade de jovens negros no Rio de Janeiro, além de uma forma de prolongar a informação estatística sobre o tema que, uma vez veiculada, cai no esquecimento. Alguns cases estudados em sua pesquisa foram os dos estilistas Zuzu Angel (que bordava referências à ditadura militar em suas roupas) e Ronaldo Fraga (que promoveu desfiles relativos ao desastre de Mariana e ao assassinato da vereadora Marielle Franco), mas o mais interessante é o de Serpica Naro. Trata-se de uma comunidade on-line surgida a partir da Euro May Day Parade - uma manifestação que luta contra a precariedade dos trabalhadores e que acontece em várias cidades da Europa no dia do trabalhador. Em 2005, o movimento conseguiu se cadastrar e desfilar oficialmente na Semana de Moda de Milão com uma grife nipo-britânica fake, encabeçada por uma suposta estilista (bastante provocadora) de mesmo nome - Serpica Naro -, denunciando, de forma irônica, as condições dos trabalhadores precários na indústria da moda italiana (LIMA, 2019, p. 75-76).

A pesquisa de Lima (2019) recolheu dados que mostram que, a cada três semanas, os assassinatos no Brasil ultrapassam o número de mortes em todos os ataques terroristas do mundo acontecidos na primeira metade de 2017 - foram 498 casos, com 3.314 vítimas fatais. Dentro do quadro de violência brasileiro, o que mais sensibilizou a pesquisadora foi " $A$ dor que não se traduz com dados estatísticos e notícias no meio da tarde. A dor de todas as mães que não conseguiram ver seus filhos crescerem" (LIMA, 2019, p. 11).

Além das premissas do papel social e político da moda, é importante reforçar o seu papel na economia como um todo, e da identidade de alguns locais, como a cidade do Rio de Janeiro, especificamente. De acordo com a Federação das Indústrias do Estado do Rio de Janeiro (Firjan), a moda é um dos quatro segmentos da grande área denominada Consumo, no seu mapeamento da Economia Criativa do Estado, respondendo, em 2017, por cerca de 50 mil empregos diretos (FIRJAN, 2017), além da economia informal que gira à sua volta. Considerando especialmente a economia informal que gira em torno da moda, Lima (2019) desenhou, como resultado de sua pesquisa, uma plataforma colaborativa sem fins lucrativos. 0 projeto prevê uma galeria de estampas relacionadas ao tema da violência entre os jovens negros no Rio de Janeiro, doadas por designers, artistas ou estilistas, que serão aplicadas em camisetas a serem produzidas on demand, cuja renda das vendas será revertida para a ONG de um grupo de mães. 0 projeto "E se fosse seu filho?" encontra-se em implantação.

\section{CONSIDERAÇÕES FINAIS}

A velha camiseta do Che, que encantou o jovem jornalista brasileiro na década de 1960, ainda faz algum sucesso, e não é raro encontrá-la nos dias de hoje. Assim como a censurada camiseta dos Sex Pistols ainda pode ser comprada pela internet. 
Os jovens sempre foram vistos como rebeldes, pois, em geral, opõem-se a alguns padrões da geração anterior. São eles os que mais se engajam em causas e, principalmente para eles, é importante demonstrar sua adesão a elas pela forma como se vestem - e a camiseta continua sendo um dos principais meios de o usuário dizer quem é.

Enquanto setor produtivo, a moda tem forte impacto no desenvolvimento econômico, embora saiba-se que nem sempre da forma mais justa. Especificamente, o design (criação) de moda é considerado um dos mais importantes setores da economia criativa, pois agrega valor simbólico ao produto (vestuário) de necessidade básica. E, também, muito especialmente, no caso do Rio de Janeiro, onde se explora o lifestyle da cidade e do seu nativo, o carioca.

A moda atravessa, ainda quase impune, o embate capitalismo vs. engajamento, mas o consumo efêmero e compulsivo de roupas é um dos mais criticados, por isso cada vez será mais importante dizer quem você é pelo que você veste. Paralelamente, fortifica-se o uso da tecnologia e das redes sociais como um poderoso instrumento para veicular causas, para efetuar compras e - juntando as duas ações - para se conhecerem os processos de trabalho que envolvem marcas, estilistas e seus produtos, e a relação desses com as questões socioambientais.

Importante ainda dizer que mais e mais trabalhos discentes têm surgido, nos últimos anos, preocupados com dados sobre a produção e o consumo responsável de moda, propondo o desenvolvimento de projetos relacionados aos movimentos minimalista e sustentável.

\section{Fashion design and socio-political engagement}

Abstract: This paper approaches the relation involving fashion and purpose or activism based on the connection perceived between three apparently very different researches simultaneously in progress in the same institution, in 2018/2019. The first is a scientific initiation research on women empowerment in punk-rock fanzines aesthetics; the second is a master's research on trends in the decision making process for the consumption of fashion in Rio de Janeiro; the third research is a master's research that treats fashion as a possible means for discussing high mortality rates of young Afro-Brazilian boys in Rio de Janeiro. Somehow, these researches span the possibility for fashion to accomplish a communicational role both as an engagement vector for users (the first and the third) and as an engagement response from consumers (the second one). The first paper is partly bibliographical and partly documental (counting on the graphic analysis of a selection of pages from the fanzines); the second is eminently qualitative (interviews and focus groups), while the third deals with studies of several cases, but proposing the materiality of a product. Thus, this paper starts from the results arising from the look performed into these researches, but brings other contributions in relation to bibliographic references.

Keywords: Fashion. Nonconformity. Purpose and activism. Consumption trends for the near future. Technology. 


\section{REFERÊNCIAS}

ANGUS, A. Top 10 global consumer trends for 2018: emerging forces shaping consumer behaviour. Londres: Euromunitor, 2017.

CLARKE, J. S.; HOLT, R. Considered consumption: Vivienne Westwood and the ethics of consuming fashion. Journal of Management Inquiry, v. 25, n. 2, p. 199-213, 2016. Disponivel em: http://eprints.whiterose.ac.uk/87157/3/Clarke\%20Westwood.pdf. Acesso em: 20 set. 2020.

DEBORD, G. A sociedade do espetáculo: comentários sobre a sociedade do espetáculo. Rio de Janeiro: Contraponto, 1997.

DRUSCO, F. D. The man who said to Westwood: "Do something romantic. Look at History" has recently died. Yet his fashion and his style will live on forever. Vogue Italia, Milan, 23 Apr. 2010. Disponivel em: https:/www.vogue.it/en/people-are-talking-about/parties-events/2010/04/malcolm-mclaren-s-fashion?refresh_ce=. Acesso em: 21 set. 2019.

FEDERAÇÃO DA INDÚSTRIAS DO ESTADO DO RIO DE JANEIRO (FIRJAN). Mapeamento da indústria criativa no Brasil. Rio de Janeiro: Firjan, 2017. Disponivel em: https://www.firjan.com. br/EconomiaCriativa/downloads/MapeamentolndustriaCriativa.pdf. Acesso em: 20 set. 2019. GONTIJO, S. 80 anos de moda no Brasil. Rio de Janeiro: Nova Fronteira, 1987.

GORDON, A. Rare Sex Pistols record previously valued at $£ 13,000$ up for auction this weekend. Spin, 16 Nov. 2017. Disponivel em: https://www.spin.com/2017/11/rare-sex-pistol-record-auction-god-save-the-queen-most-expensivel. Acesso em: 18 set. 2019.

HENRY, T. Break all rules! Punk rock and the making of a style. Michigan: UMI Research Press, 1989.

KELLY, I.; WESTWOOD, V. Vivienne Westwood. Rio de Janeiro: Rocco, 2014.

LIMA, P. M. Vestir a luta: a moda como veículo de sensibilização sobre a violência contra jovens negros no Brasil. 2019. Dissertação (Mestrado Profissional em Gestão da Economia Criativa) - Escola Superior de Propaganda e Marketing, Rio de Janeiro, 2019.

LIPOVETSKY, G.; SERROY, J. A estetização do mundo: viver na era do capitalismo artista. São Paulo: Companhia das Letras, 2015.

MOTTA, N. A camiseta do Che: a liberdade e a fartura americanas me impressionaram. 0 Globo, Opinião, 25 jan. 2019. Disponivel em: https://oglobo.globo.com/opiniao/a-camisetado-che-23399784. Acesso em: 10 set. 2019.

O'HAGAN, S. Fifty years of pop. The Observer, London, 2 May 2004. Disponivel em: https:// www.theguardian.com/music/2004/may/02/popandrock. Acesso em: 15 out. 2019. 
RODRIGUES, I. O Rio que virou moda. Rio de Janeiro: Memória Brasil, 1994.

STOCCO, G. Tendências no comportamento de compra do consumidor carioca: um estudo do perfil dos consumidores cariocas de moda para a década de 2020. 2019. Dissertação (Mestrado Profissional em Gestão da Economia Criativa) - Escola Superior de Propaganda e Marketing, Rio de Janeiro, 2019.

THE FILTH and the fury: a Sex Pistols film. Direction: Julien Temple. London: Film Four, 2000. (108 $\mathrm{min})$, color.

WORTH GLOBAL STYLE NETWORK (WGSN). 0 consumidor do futuro 2020: previsão de consumo. New York: WGSN Internacional, 2018. Disponivel em: https://www.wgsn.com/wp-content/uploads/el-consumidor-do-futuro-2020WGSN-pt.pdf. Acesso em: 10 out. 2019. 